\title{
To applicability of surgical correction for brachymetatarsia in children
}

\author{
O.V. Kozhevnikov, A.A. Ochkurenko, A.V. Ivanov, I.V. Gribova, S.E. Kralina, Yu.V. Gavrilova
}

National Medical Research Center of Traumatology and Orthopedics n.a. N.N. Priorov, Moscow, Russian Federation

\begin{abstract}
Introduction Correction of brachymetatarsia is performed by lengthening with various means. The necessity of metatarsal bone lengthening in brachymetatarsia is debatable. Material and methods From 2004 to 2018, surgical correction of brachymetatarsia was performed in 13 patients (age range, 6-18 years). Biomechanics of walking was studied in the preoperative and long-term postoperative period. Results The goal of surgical correction was achieved in all cases. AOFAS score scale was used for assessment of functional status. The mean score increased from 57.0 to 93.6 points. Time and kinematic characteristics of walking improved 18 months after reconstruction. Discussion Due to pain, discomfort and cosmetic defects the patients seek medical care even if marked functional disorders are absent in brachymetatarsia. The analysis of walking in patients with unilateral brachymetatarsia shows difference between the sides, as well as a deviation from the age norm on the side of brachymetatarsia. As far as motor skills complete to be formed by 7 years of age and close-to-adults walking by 13 years, it seems appropriate to perform surgical correction of brachymetatarsia in this period. Conclusion Lengthening of metatarsal bones improves weight-bearing of the foot, ensuring the correct walking skills and smoothness of gait. Restoration of the fourth metatarsal bone, along with elimination of metatarsalgia, improves the esthetic appearance and allows wearing normal shoes. The compression-distraction method enables to solve the problem of elongation of short tubular bones in brachymetatarsia.
\end{abstract}

Keywords: brachymetatarsia, compression-distraction method, walking biomechanics, children

\section{INTRODUCTION}

Brachimetarsia is an orthopedic disease, manifested by hypoplasia of one or more metatarsal bones. Brachymetatarsia is a significant cosmetic defect, but changes the biomechanics of walking if the first metatarsal bone is involved. The condition accounts for $0.05 \%$ of incidence among the pathology of the musculoskeletal system [1]. More frequently, this developmental anomaly of the foot is first noted at the age of one to 5 years. The disease is associated with an early closure of the epiphyseal plates of the metatarsal bones. Brachymetatarsia may be one of the manifestations of the stigma of dysembryogenesis in combination with brachydactyly, brachymetacarpia, Aper and Down syndromes [2-5]. There is data on the geography of brachymetatarsia morbidity. In Korea, a unilateral involvement of the foot anomaly prevails while more than half of patients have bilateral involvement in Japan, the USA and in a number of European countries $[3,6]$. Normal biomechanics of walking is ensured by the correct anatomy of the foot. The length of the first metatarsal bone is decisive in the architectonics of the forefoot. The shortened first metatarsal bone causes a disorder in the metatarsal parabolic arch of Lellère and affects the support function of the forefoot, changing the biomechanics of walking, leading to overloading of the heads of the second and third metatarsal bones, their subsequent deformity, and inevitably leads to the appearance of metatarsal pain [7-9]. It is obvious that the inequality in the length of one of several short tubular bones of the foot will not cause such significant biomechanical disorders as the ones observed in the lower extremity length discrepancy [10].

The opinion on the utility of correcting the inequality in the length of the metatarsal bones in children is based on the study of walking characteristics in the age aspect [11]. The only possible treatment for brachymetatarsia is surgical which is able to eliminate the inequality in the length of the metatarsal bones and restore the metatarsal parabolic arch [12-14]. Correction methods consist in acute lengthening of the metatarsal bone, including with auto/allograft bone [15-17], or with compressiondistraction method [18-21]. Elongation of the metatarsal bone by more than $1.5 \mathrm{~cm}$ is associated with the risk of distension complications due to overstretching of the neurovascular structures, tendons and skin. The use of autografts in children is limited due to unclosed growth zones and a small number of "donor" sites in the pediatric skeleton. The use of allografts is associated with all known risks: infection, contamination with donor viruses, early graft resorption with loss of correction. The distraction method avoids the above complications and ensures lengthening of the segment to the required 
amount, while there is no need for auto/allograft bone. The low rate of osteoreparative ability of the metatarsal bones due to dysplastic changes in the connective tissue can be attributed to distraction method shortcomings.

Purpose - presentation of argumentation in favor of surgical treatment of brachymetatarsia in children.

\section{MATERIAL AND METHODS}

Surgical correction of brachymetatarsia was performed in 13 patients aged from six to 18 years at the traumatology and orthopedic children's department 10 of FSBI NMRC for TO named after N.N. Priorov in the period between 2004 and 2018. Twelve patients had congenital pathology; there was one patient with an acquired discrepancy in the length of the metatarsal bones. Brachymetatarsia of the first metatarsal bone was present in five patients (bilateral in two cases, combined with varus deviation of the first toes and syndactyly of the second to third toes of both feet in one case); eleven patients had hypoplasia of the fourth metatarsal bone.

All studies in the clinic were carried out in accordance with current requirements; the principles of the Helsinki Declaration "Ethical Principles for Conducting Scientific Medical Research with Human Participation" (as amended in 2000) were followed. SPSS Statistics software was used for statistical analysis [22]. Functional status was evaluated with the American Orthopedic Association of Foot and Ankle Surgery (AOFAS) system [23]. Patients or their legal representatives signed informed consents for preoperative examination, surgical intervention, use of clinical material for research and scientific publications.

Examination included a clinical examination, radiography in two projections (frontal and lateral) and a functional study of the biomechanics of walking. At the stages of lengthening, the dynamics of ossification of the regenerate was assessed radiographically.

Clinical examination evaluated the shape of the foot, its fore part and the correspondence of the toe arch to one of the formulas: " $1<2>3>4>5$ ", " $1>2>3>4>5$ ", “ $1=2 \geq 3 \geq 4 \geq 5$ " [24]. In cases with hypoplasia of the 1st metatarsal bone, an increase in the height of the internal longitudinal arch and its smaller extension was common. Flattening of the anterior arch, coarse skin along the plantar surface of the feet in the area of $2^{\text {nd }}$ to $4^{\text {th }}$ metatarsal bones was noted in all patients. A functional tip-toe test was performed, which could reveal the absence of support on the head of the first metatarsal bone, as well as Grifka and Strunsky tests which reveal pain in the metatarsophalangeal joints and pain in the metatarsal region [25].

Metatarsal parabola disorders due to the shortening of a metatarsal bone were visualized in radiographs; structural changes were noted in the $4^{\text {th }}$ metatarsal bones such as hypoplasia of its diaphyseal part and a decrease in the intensity of the radiological shadow of the head. In the metatarsal bones, the intensity of the radiological shadows was not different from the rest of the bones.

The biomechanics of walking was studied using the ELITE-2002 hardware-software complex (BTS, Italy). We studied the basic and temporal parameters of walking, which directly reflect the gait characteristics (walking pace, speed of movement, stride length, support phase, rhythm coefficient), kinematic (characterizing angular movements in the joints of the lower extremities), and dynamic parameters (reflecting the supporting reaction vectors). Dynamic parameters were compared with the age norm [11].

All patients underwent surgical treatment. Elongation of the metatarsal bones was performed in 13 patients on 15 metatarsal bones. Surgical correction included the placement of an external compression-distraction apparatus on the foot and osteotomy of the metatarsal bone. The fixator was assembled in two variants: a wirehalfpin hybrid consisting of a base part (two half-rings of the Ilizarov apparatus connected by threaded rods) and a dynamic part assembled from the components of a small half-pin based apparatus (used in 4 patients), or an entire small half-pin based distraction apparatus KUD- SAI-01 for osteosynthesis of small tubular bones manufactured by FSUE "CITO" (used in 9 patients; with an axial wire in an elongated bone in 2 cases). When the halfpins passed through the metatarsal bone, the function of flexion and extension in the metatarsophalangeal joint was controlled in a passive mode to exclude fixation of extensor tendons. An osteotomy was performed with an osteotom, as close as possible to the metaphyseal part of the metatarsal bone. The apparatus was oriented in the sagittal direction to exclude secondary varus deformity of the calcaneal part of the foot in lengthening of the $1^{\text {st }}$ metatarsal bone.

The rate of distraction ranged from 0.5 to $0.75 \mathrm{~mm}$ per day. Distraction lasted an average of 38 days.

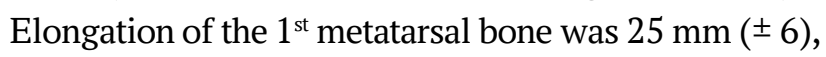
of the $4^{\text {th }}$ metatarsal bone $23 \mathrm{~mm}( \pm 7)$. The fixator was dismantled in 45-64 days. The fixation index ranged from $20.0 \pm 3.8$ days $/ \mathrm{cm}$, the osteosynthesis index ranged from $42.1 \pm 3.2$ days $/ \mathrm{cm}$. 


\section{RESULTS}

Studying the biomechanics of walking in patients with brachymetatarsia of the 4th metatarsal bones, significant deviations from the age norm, as well as a pronounced difference in the kinematic and dynamic parameters of walking on both sides were not noted. Disorders (deviation compared with the healthy side and age group) were observed in patients with discrepancy in the length of the $1^{\text {st }}$ metatarsal bones. Duration of the stride relative to the opposite side was shorter by walking at an arbitrary pace. The ratio of the duration of the limb swing over the support and the roll-over on the intact limb was increased; it was reduced on the side of brachymetatarsia. The weight-bearing duration on the healthy limb was increased. The value of the maximum load on foot compartments in standing and walking positions was reduced; the frontal and posterior strikes of the foot with brachymetatarsia were reduced.

AOFAS functional status assessment was performed in nine patients 18 months after surgical treatment. The average AOFAS score increased from 57 to 93.6 points $(\mathrm{p}<0.05)$. The results of treatment of brachymetatarsia are presented in Table 1 .

Table 1

Evaluation of the treatment results in brachymetatarsia with the AOFAS score after 18 months $(n=9)$

\begin{tabular}{|l|c|c|}
\hline Foot functions (points) & $\begin{array}{c}\text { Before } \\
\text { correction }\end{array}$ & $\begin{array}{c}\text { After surgical } \\
\text { correction }\end{array}$ \\
\hline Excellent (95-100) & 0 & $3(33.3 \%)$ \\
\hline Good (75-94) & 0 & $5(55.5 \%)$ \\
\hline Fair (51-94) & $5(55.5 \%)$ & $1(11.1 \%)$ \\
\hline Poor (50 or less) & $4(44.4 \%)$ & 0 \\
\hline Total & $9(100 \%)$ & $9(100 \%)$ \\
\hline
\end{tabular}

\section{Complications}

No serious complications were noted in patients with brachymetatarsia treated. The tasks of lengthening, achieving the required bone length, were performed in an acceptable time term in all cases. Soft tissue cuts occurred in bone elongation, despite attempts to create a reserve of skin in the area of distraction. A small supply of skin and subcutaneous fat on the dorsal foot is due to its anatomy. We prevented circulation disorders in the skin by reducing the rate of distraction and using drugs that improve microcirculation and level manifestations of spasms of the skin vessels, as well as improve trophic function (nicotinic acid, dipyridamole, vitamins B -thiamine, pyridoxine, cyanocobalamin).

It should be noted that in no case did it become necessary to reassemble or prematurely dismantle the external fixator, as well as to complete the distraction before length compensation was achieved. No additional surgery was required in these patients.

Case report Patient F., 12 years old, was admitted to the department complaining of an esthetic defect, discomfort, and pain in the right foot during exercise. Foot asymmetry was noticed by parents at four years of age. Deficit of the first ray length of the foot advanced as the child was growing; by the time of treatment, length inequality was perceived as a pronounced esthetic defect and was accompanied by pain in the forefoot.

The patient walked without additional supports. The gait was not rhythmic, internal rotation of the forefoot of the right limb was about $7^{\circ}$. The appearance of the right foot was distorted and the toe arch was deformed (Fig. 1 a). The length deficit of the first ray in the right foot was $2.5 \mathrm{~cm}$. By lifting to the half-toes ("tip-toe" test), the support passed on the heads of the $2^{\text {nd }}$ and $3^{\text {rd }}$ metatarsal bones of the right foot and on the heads of the $1^{\text {st }}$ and $2^{\text {nd }}$ metatarsal bones of the left foot (physiological) (Fig. 1 b). Active movements in $1^{\text {st }}$ metatarsophalangeal joint of the right foot were extension $30^{\circ}$, flexion $10^{\circ}$. Passive movements were extension $30^{\circ}$, flexion $20^{\circ}$. Right ankle joint movements were flexion $25^{\circ}$, extension $10^{\circ}$. The radiograph (Fig. $1 \mathrm{c}$ ) revealed a $2.5-\mathrm{cm}$ discrepancyt in the length of the $1^{\text {st }}$ metatarsal bone of the right foot, the articular surface of the head of the metatarsal bone outside the metatarsal parabola, deformed $1^{\text {st }}$ metatarsal bone, and a secondary deformation of the navicular bone.

The patient's dynamic walking parameters had a difference with the contralateral limb and differed from the normal parameters of the age group (Table 2).

The patient's metatarsal bone lengthening was performed by compression-distraction method which comprised wires and half-pins (Fig. 2, a, b).

Transverse osteotomy of the 1st metatarsal bone was produced from a minimal approach by means of an osteotom (Fig. 2, c, d). The distraction continued 40 days. The rate of distraction ranged from 0.5 to $0.75 \mathrm{~mm}$ per day. During the entire period of treatment, the patient walked with the help of crutches withpartial support on the foot in the plantar plaster cast. The fixation index was 16 days per $1 \mathrm{~cm}$ of lengthening; the osteosynthesis index was 40 days per $1 \mathrm{~cm}$ of elongation. After the apparatus was dismantled, customized orthoses for the foot were used, and a rehabilitation course aimed at 
restoring the range of motion in the metatarsophalangeal joints of the right foot was indicated.

The appearance of the right foot was corrected which contour of the toe arch was smooth and corresponded to the left foot (Fig. 3).

By lifting to half-toes ("tip-toe" test), the support is on the heads of the 1st and 2nd metatarsal bones of the right foot similarly to the left foot (Fig. 3, b). In the
X-ray (Fig. 3 c), the metatarsal parabola is restored.

According to the examination 18 months after the surgical correction, the indicators of the foot support reactions improved (Table 3).

The results of treatment of patient $F$. on the AOFAS scale were 96 points as compared with the initial 59 points, which reflects a positive result of the correction of brachymetatarsia.
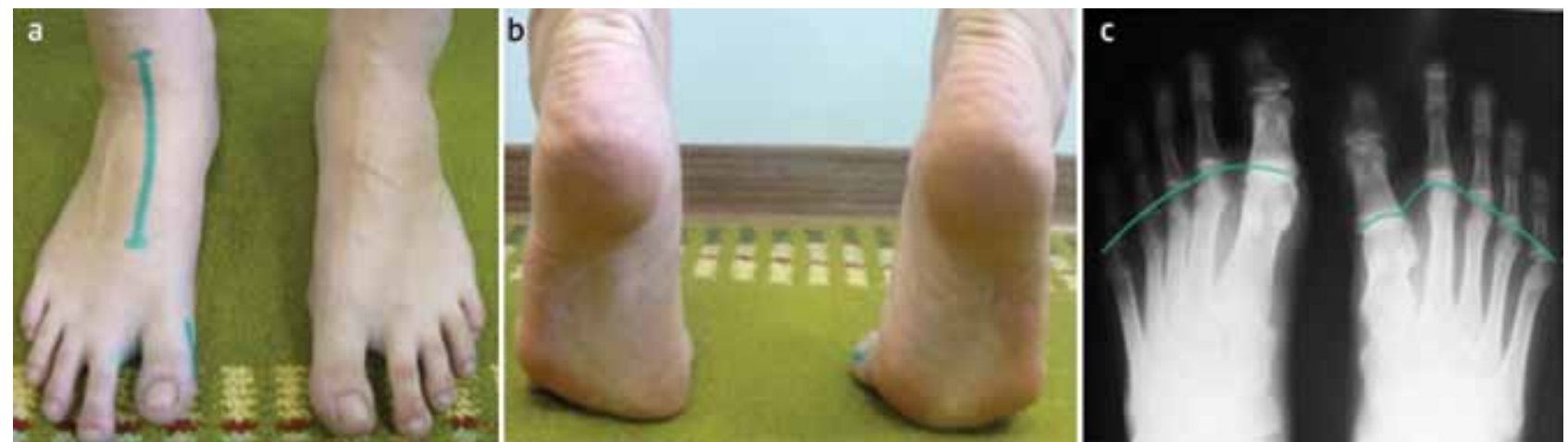

Fig. 1 Appearance of the feet of patient F. (a); tip-toe test performed by the patient showing asymmetric support on forefoot (b); AP X-ray of the feet showing different length of the metatarsal bones, the discrepancy in the length of the $1^{\text {st }}$ metatarsal bone of the right foot is $2.5 \mathrm{~cm}(\boldsymbol{c})$

Table 2

Extreme values of support reactions in patient $\mathrm{F}$ before correction and reference group norm

\begin{tabular}{|c|c|c|c|}
\hline Parameters of SR* & Support element & Before operation & Norm** \\
\hline \multicolumn{4}{|c|}{ Left foot } \\
\hline $\begin{array}{l}\text { Anterior strike } \\
\text { minimum } \\
\text { posterior strike }\end{array}$ & $\mathrm{R}_{\mathrm{z}}^{*}$ & $\begin{array}{c}106.7 \\
73.2 \\
115.1 \\
\end{array}$ & $\begin{array}{c}108.0 \pm 3.5 \\
71.9 \pm 2.0 \\
115.4 \pm 2.6\end{array}$ \\
\hline $\begin{array}{l}\text { Anterior strike } \\
\text { Posterior strike }\end{array}$ & $\mathrm{R}_{\mathrm{x}}^{*}$ & $\begin{array}{l}16.9 \\
17.6\end{array}$ & $\begin{array}{l}17.6 \pm 0.9 \\
19.5 \pm 1.2\end{array}$ \\
\hline \multicolumn{4}{|c|}{ Right foot (brachymetatarsia) } \\
\hline $\begin{array}{l}\text { Anterior strike } \\
\text { minimum } \\
\text { posterior strike }\end{array}$ & $\mathrm{R}_{\mathrm{z}}^{*}$ & $\begin{array}{c}87.5 \\
80.1 \\
101.3\end{array}$ & $\begin{array}{c}107.7 \pm 2.8 \\
70.5 \pm 2.4 \\
109.1 \pm 2.6\end{array}$ \\
\hline $\begin{array}{l}\text { Anterior strike } \\
\text { Posterior strike }\end{array}$ & $\mathrm{R}_{\mathrm{x}}^{*}$ & $\begin{array}{l}14.9 \\
14.6\end{array}$ & $\begin{array}{l}18.3 \pm 1.3 \\
19.2 \pm 1.1\end{array}$ \\
\hline
\end{tabular}

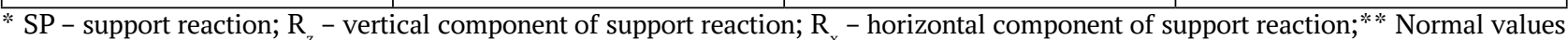
in age group according to Vitenzon AS
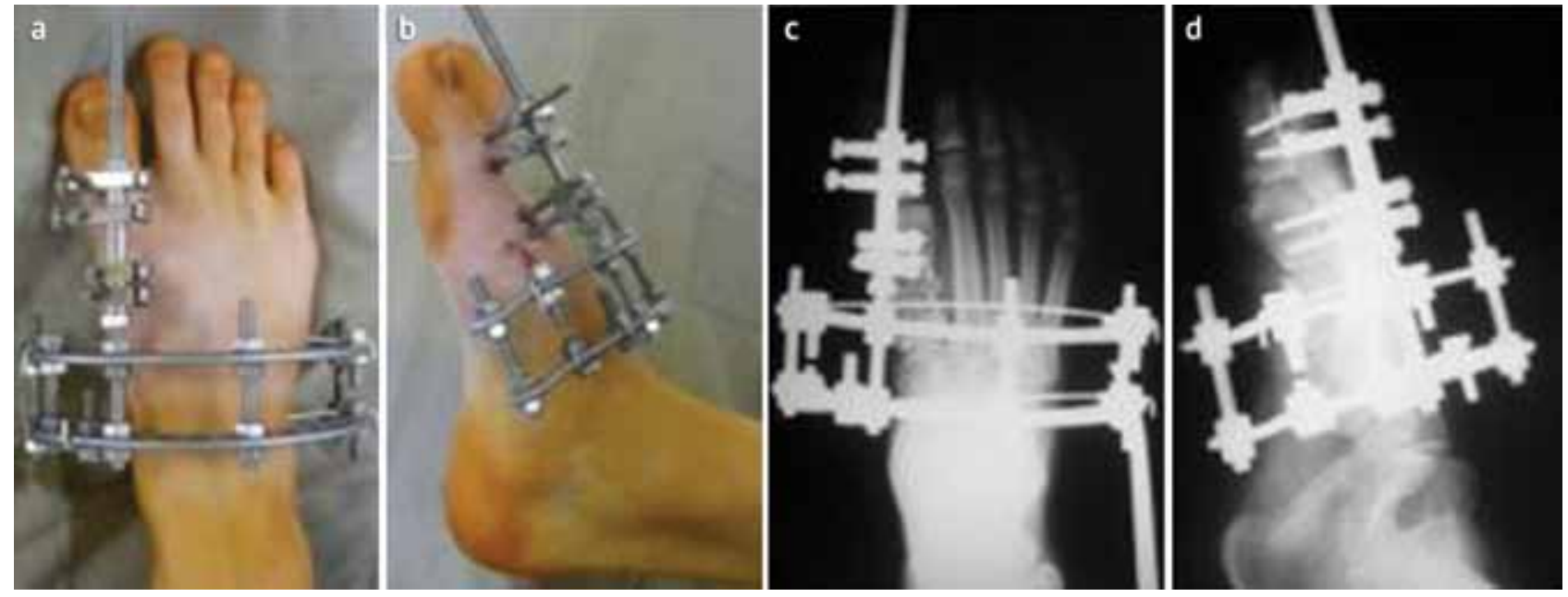

Fig. 2 View of the foot with a compression-distraction apparatus on $(\boldsymbol{a}, \boldsymbol{b})$; radiographs of the foot in the frontal $(\boldsymbol{c})$ and lateral (d) projection 

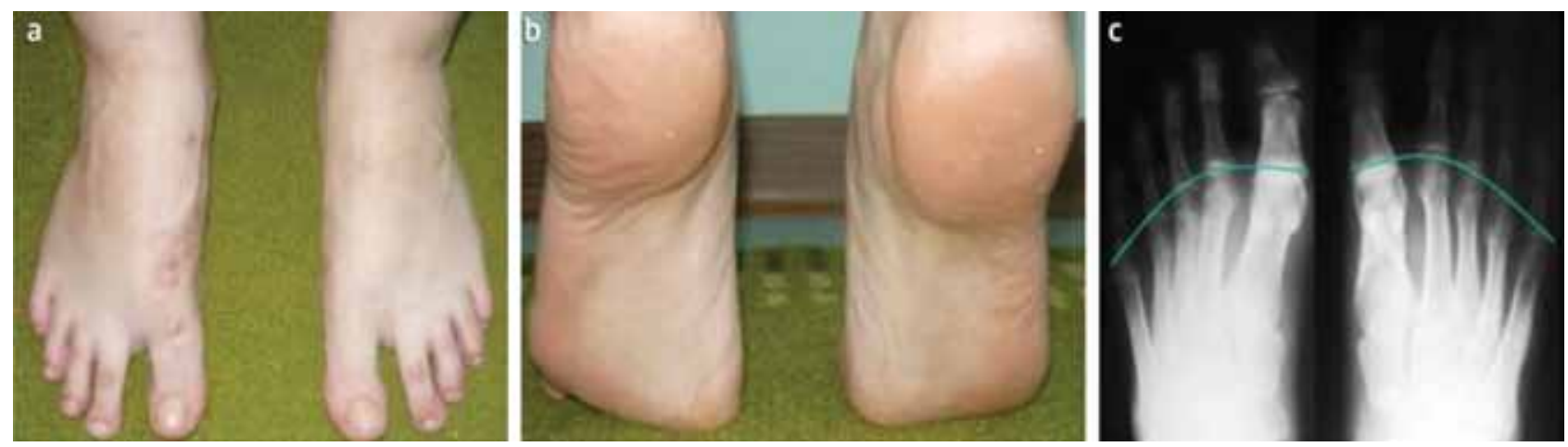

Fig. 3 Views of the feet of patient $\mathrm{F}$ after surgical treatment (a); tip-toe test performed by the patient; loading on both forefeet is comparable $(\boldsymbol{b})$; AP X-ray of the feet showing the length of the first metatarsal bone restored $(\boldsymbol{c})$

Table 3

Extreme values of support reactions in patient F. 18 months after surgery

\begin{tabular}{|c|c|c|c|c|}
\hline Parameters of SR* & Support element & After operation & \% to initial value & Norm*** \\
\hline \multicolumn{5}{|c|}{ Left foot } \\
\hline $\begin{array}{l}\text { Anterior strike } \\
\text { minimum } \\
\text { posterior strike }\end{array}$ & $\mathrm{R}_{\mathrm{z}}$ & $\begin{array}{c}109.8 \\
74.2 \\
116.2\end{array}$ & $\begin{array}{l}103 \\
101 \\
101\end{array}$ & $\begin{array}{c}107.7 \pm 2.8 \\
70.5 \pm 2.4 \\
109.1 \pm 2.6\end{array}$ \\
\hline $\begin{array}{l}\text { Anterior strike } \\
\text { posterior strike }\end{array}$ & $\mathrm{R}_{\mathrm{x}}$ & $\begin{array}{l}17.3 \\
19.0 \\
\end{array}$ & $\begin{array}{l}102 \\
108 \\
\end{array}$ & $\begin{array}{l}17.7 \pm 0.9 \\
20.1 \pm 0.9 \\
\end{array}$ \\
\hline \multicolumn{5}{|c|}{ Right foot (brachymetatarsia) } \\
\hline $\begin{array}{l}\text { Anterior strike } \\
\text { minimum } \\
\text { posterior strike }\end{array}$ & $\mathrm{R}_{\mathrm{z}}$ & $\begin{array}{r}99.8 \\
76.4 \\
105.9\end{array}$ & $\begin{array}{c}114 \\
95 \\
105\end{array}$ & $\begin{array}{c}107.7 \pm 2.8 \\
70.5 \pm 2.4 \\
109.1 \pm 2.6\end{array}$ \\
\hline $\begin{array}{l}\text { Anterior strike } \\
\text { posterior strike }\end{array}$ & $\mathrm{R}_{\mathrm{x}}$ & $\begin{array}{l}17.2 \\
17.9\end{array}$ & $\begin{array}{l}115 \\
122\end{array}$ & $\begin{array}{l}17.7 \pm 0.9 \\
20.1 \pm 0.9\end{array}$ \\
\hline
\end{tabular}

** Norms of the age group (A.S. Vitenzon)

\section{DISCUSSION}

Discrepancy in the length of the metatarsal bones does not cause such pronounced motor disorders and adaptive compensatory changes in the motor stereotype as it happens in the pathology of large joints of the lower extremities or in the different length of the lower extremities [10]. However, discomfort and pain during prolonged static loads, affecting the functional status, make patients seek medical help. Is brachymetatarsia an insignificant orthopedic defect? In our opinion, it is not. According to A. Vitenzon, "the biomechanical structure of the locomotor function develops completely to the age of 7 years" [11]. But, patients refer to treating brachymetatarsia at an older age. According to the same literary source, "7-to-8 year old, have a higher vertical component $\mathrm{Rz}$ in the anterior strike phase than adults", and as the age grows, the amplitudes in the anterior and posterior impulse phases become comparable, which indicates "the development of a smoother support" [11]. Thus, in the process of "growing up" there is a gradual increase in loads on the forefoot and "by the age of 13 years old, walking characteristics are approaching the adult norm" [11]. Analysis of the dynamic characteristics of walking in patients with unilateral brachymetatarsia reveals a difference between the sides, as well as a difference from age norms on the side of brachymetatarsia. Thus, full foot support is necessary, in our opinion, to be completed by 13 years of age.

The choice of a method for correcting the discrepancy in the length of the metatarsal bones, as well as a number of other orthopedic conditions, is completely the competence of a surgeon. In our case, it is a compressiondistraction method. This is largely due to technical points, namely, small half-pin distraction elements for osteosynthesis of small tubular bones (KUD-SAI-01), as well as the features of alloplastic bone material available to us. These are two main factors that determine the priority of surgical tactics using transosseous osteosynthesis. Not having our own experience of acute lengthening of the metatarsal bones, we focus on the published data. The complications presented in the reports, caused by acute distraction of bone fragments [6], are more significant than the drawbacks of the distraction method described above by the authors, such as the need to manipulate the external structure, "weakness" of the distraction regenerate and possible local infection. Most of these complications are typical for transosseous osteosynthesis 
and are eliminated during treatment [13]. Perhaps, due to a small size of our study group, we did not encounter anything that went beyond the typical treatment with compression distraction devices.

Skin cuts in the area of the half-pins and wires is a frequent during distraction in the apparatus, we do not regard this as a complication. The dorsal foot (at normal weight of the patient) always has undeveloped subcutaneous fat. As a result, even if a skin fold in the distraction area is created during the placement of apparatus, skin cutting is inevitable. On the plantar surface of the foot in all our patients, we noted coarse skin in the projection of the metatarsophalangeal joint of the ray affected with brachymetatarsia. W.-C. Lee et al. indicate the formation of maceration in the projection of the skin fold during fixation of the fourth toe in the position of plantar flexion during lengthening. We are inclined to consider this as the errors of skin care. We fixed the fourth toe in the plane of the other toes of the foot which facilitated the gradual rearrangement of the subcutaneous fat on the plantar surface of the forefoot when the patient partially bears weight on the foot. It can be assumed that the external distraction structure on the foot is not convenient, but it should be noted that after acute lengthening of the metatarsal bone, fixation in a plaster cast takes a comparable time period but weight-bearing is excluded for at least 8 weeks [24]. Distraction could be produced by the patient himself in an outpatient setting and was an ordinary event.
There is a comparative analysis of various methods of treatment of brachymetatarsia in the literature, and the authors' conclusions are diametrically opposed $[6,24]$. Adherents of the distraction method $[13,14$, 20] actively use it in their practice. Most likely, a certain role is played by the experience of using one or another method of surgical correction, traditions at a medical institution, and the patient's commitment to one or another method and specialist.

One of the most important advantages of the distraction method is a low invasive osteotomy, which can be produced through a minimal approach with a narrow osteotom without significant exposure of the bone. There is no need to use oscillating saws, "cauterizing" the ends of bone fragments, thereby eliminating thermal damage to the bone, and trophic function is preserved. Z-shaped sliding osteotomies and techniques using grafts require wide access to the bone, exposure over a significant extension, including for ensuring fixation with implants (plates).

The external fixator provides an early loading on the foot almost from the very beginning of distraction, which stimulates the processes of osteoreparation and, ultimately, a favorable functional result after dismantling the apparatus, reducing the time of the rehabilitation period. A similar but even more active patients' management was reported in the work of A. Neretin et al., who allow weight-bearing on the foot from the $2^{\text {nd }}$ day after the operation to ensure good regeneration [13].

\section{CONCLUSION}

Surgical correction of brachymetatarsia is habits and smooth gait. Restored length of the fourth advisable in childhood from the age of seven to 13 years. The restoration of the length of the first metatarsal bone improves the appearance and supportability of the foot, ensures the correct distribution of the load on its parts, correct walking metatarsal bone not only relieves pain but also improves the appearance of the foot and wearing a variety of shoe designs. The compression-distraction method solves the problem of lengthening short tubular bones in brachymetatarsia.

Source of funding The study was not funded.

Conflict of interest The authors declare no apparent or potential conflicts of interest related to the publication of this article.

Ethical issues The authors received written voluntary consents of the patients (their legal representatives) to perform surgical interventions and use their clinical material for scientific purposes. This article is a retrospective clinical study and is not part of any research project.

\section{REFERENCES}

1. Schimizzi A., Brage M. Brachymetatarsia. Foot Ankle Clin., 2004, vol. 9, no. 3, pp. 555-570. DOI: 10.1016/j.fcl.2004.05.002.

2. Kozlova S.I., Demikova N.S. Nasledstvennye sindromy i mediko-geneticheskoe konsultirovanie: atlas-spravochnik: ucheb. posobie dlia studentov med. VUZov i poslediplomnogo obrazovaniia [Hereditary syndromes and medical-genetic consulting: atlas-reference book: manual for students of medical higher education institutions and postgraduate education]. M., Tovarishchestvo nauch. izd. KMK: Avt. Akad., 2007, 447 s. (in Russian)

3. Kirkos J.M. Idiopathic symmetrical shortening of the fourth and fifth metacarpal and metatarsal bilaterally. A case report. Acta Orthop. Belg., 1999, vol. 65, no. 4, pp. 532-535.

4. Munuera Martínez P.V., Sotillos L.G., Maldonado D.G., Macías S.J.L., Camuna M.L. Morphofunctional study of brachymetatarsia of the fourth metatarsal. J. Am. Podiatr. Assoc., 2004, vol. 94, no. 4, pp. 347-352. DOI: 10.7547/0940347. 
5. Tachdjian M.O. "Disorders of the foot” in Tachdjian's Pediatric Orthopaedics. Herring J.A., Saunders W.B. eds. Philadelphia, 1990.

6. Lee W.C., Yoo J.H., Moon J.S. Lengthening of fourth brachymetatarsia by three different surgical techniques. J. Bone Joint Burg. Br., 2009, vol. 91, no. 11, P. 1472-1477. DOI: 10.1302/0301-620x.91b11.22169.

7. Vitenzon A.S. Zakonomernosti normalnoi i patologicheskoi khodby cheloveka [Patterns of normal and pathological human walking]. M., TsNIIPP, 1998, 271 p. (in Russian)

8. Koniukhov M.P., Klychkova I.Iu., Kovalenko-Klychkova N.A., Nikitiuk I.E. Poroki razvitiia pervogo lucha stopy u detei: diagnostika, klinika, lechenie [Malformations of the first ray of the foot in children: diagnosing, clinical picture, treatment]. Ortopediia, Travmatologiia i Vosstanovitelnaia Khirurgiia Detskogo Vozrasta, 2015, vol. 3, is. 2, pp. 15-24. (in Russian) DOI: 10.17816/PTORS3215-24.

9. Maestro M., Besse J.L., Ragusa M., Berthonnaud E. Forefoot morphotype study and planning method for forefoot osteotomy. Foot Ankle Clin., 2003, vol. 8, no. 4, pp. 695-710. DOI: 10.1016/S1083-7515(03)00148-7.

10.Shchurov V.A., Novikov K.I., Muradisinov S.O. Vliianie raznovysokosti nizhnikh konechnostei na biomekhanicheskie parametry khodby [The influence of different height of the lower limbs on biomechanical parameters of walking]. Rossiiskii Zhurnal Biomekhaniki, 2011, vol. 15, no. 4, pp. 102-107. (in Russian)

11.Vitenzon A.S., Petrushanskaia K.A., Spivak B.G., Matveeva I.A., Gritsenko G.P., Sutchenkov I.A. Osobennosti biomekhanicheskoi struktury khodby u zdorovykh detei raznogo vozrasta [Special features of biomechanical structure of walking in normal children of different age]. Rossiiskii Zhurnal Biomekhaniki, 2013, vol. 17, no. 1, pp. 78-93. (in Russian)

12.Bartolomei F.J. Surgical correction of brachymetatarsia. J. Am. Podiatr. Med. Assoc., 1990, vol. 80, no. 2, pp. 76-82. DOI: $10.7547 / 87507315-80-2-76$.

13.Neretin A.S., Ivanov G.P., Danilkin M.Iu. Udlinenie kostei perednego otdela stopy metodom chreskostnogo osteosinteza po Ilizarovu [Lengthening of the bones of the forefoot by the transosseous osteosynthesis method according to Ilizarov]. Genij Ortopedii, 2011, no. 2, pp. 54-59. (in Russian)

14.Haleem A.M., Balagadde A., Borst E.W., Fragomen A.T., Rozbruch S.R. Distraction osteogenesis for brachymetatarsia: Clinical Results and implications on the metatarsophalangeal joint. J. Limb Lengthen. Reconstr., 2015, vol. 1, pp. 29-37. DOI: 10.4103/2455-3719.168746.

15.Kline A., Garden E. Brachymetatarsia: One-Stage Correction using a Cadaver Bone Allograft. The Foot and Ankle Online Journal, 2009, vol. 2, no. 5, pp. 1. DOI:10.3827/faoj.2009.0205.0001.

16.Smolle E., Scheipl S., Leithner A., Radl R. Management of congenital fourth brachymetatarsia by additive autologous lengthening osteotomy (AALO): a case series. Foot Ankle Int., 2015, vol. 36, no. 3, pp. 325-329. DOI: 10.1177/1071100714557520.

17.Jones M.D., Pinegar D.M., Rincker S.A. Callus Distraction versus Single-Stage Lengthening with Bone Graft for Treatment of Brachymetatarsia: A Systematic Review. J. Foot Ankle Surg., 2015, vol. 54, no. 5, pp. 927-931. DOI: 10.1053/j.jfas.2015.02.013.

18.Shim J.S., Park S.J. Treatment of brachymetatarsia by distraction osteogenesis. J. Pediatr. Orthop., 2006, vol. 26, no. 2, pp. $250-254$. DOI: 10.1097/01.bpo.0000214922.18186.06.

19.Kitabata R., Sakamoto Y., Nagasao T., Kishi K. Distraction Osteogenesis for Brachymetatarsia by Using Internal Device. Plast. Reconstr. Surg. Glob. Open, 2017, vol. 5, no. 7, pp. e1381. DOI: 10.1097/GOX.0000000000001381.

20.Lamm B.M., Paley D., Herzenberg J.E. Percutaneous Distraction Osteogenesis for Treatment of Brachymetatarsia. In: Scuderi G., Tria A. eds. Minimally Invasive Surgery in Orthopedics. New York, NY, Springer, 2010, pp. 435-442. DOI: 10.1007/978-0-387-76608-9-53.

21.Scher D.M., Blyakher A., Krantzow M. A modified surgical technique for lengthening of a metatarsal using an external fixator. HSS J., 2010, vol. 6, no. 2, pp. 235-239. DOI: 10.1007/s11420-010-9160-5.

22.Bühl A., Zöfel P. SPSS Version 10. Einführung in die moderne Datenanalyse unter Windows. 7 Auflage. München, Boston, San Francisco, 2000. (Russ. ed.: Biuiul A., Tsefel P. SPSS: iskusstvo obrabotki informatsii. SPb., DiaSoftIuP, 2005, 602 p.).

23.Kitaoka H.B., Alexander I.J., Adelaar R.S., Nunley J.A., Myerson M.S., Sanders M. Clinical rating systems for the ankle-hindfoot, midfoot, hallux, and lesser toes. Foot Ankle Int., 1994, vol. 15, no. 7, pp. 349-353. DOI: 10.1177/107110079401500701.

24.Kovalenko-Klychkova N.A. Lechenie brakhimetatarzii u detei [Treatment of brachymetatarsia in children]. Travmatologiia $i$ Ortopediia Rossii, 2014, no. 2 (72), pp. 53-61. (in Russian)

25.Bukup K., Bukup I. Klinicheskoe issledovanie kostei, sustavov i myshts. Testy. Simptomy. Diagnoz [Clinical Study of Bones, Joints and Muscles. Tests. Symptoms. Diagnosis]. 3rd Ed. M., Med. Lit., 2018, 384 p. (in Russian)

Received: 15.10 .2019

\section{Information about the authors:}

1.Oleg V. Kozhevnikov, M.D., Ph.D.,

National Medical Research Center of Traumatology and Orthopedics n.a. N.N. Priorov, Moscow, Russian Federation

2. Aleksandr A. Ochkurenko, M.D., Ph.D.,

National Medical Research Center of Traumatology and Orthopedics n.a. N.N. Priorov, Moscow, Russian Federation

3. Aleksey V. Ivanov, M.D., Ph.D.,

National Medical Research Center of Traumatology and Orthopedics n.a. N.N. Priorov, Moscow, Russian Federation

4. Inna V. Gribova, M.D., Ph.D.,

National Medical Research Center of Traumatology and Orthopedics n.a. N.N. Priorov, Moscow, Russian Federation

5. Svetlana E. Kralina, M.D., Ph.D.,

National Medical Research Center of Traumatology and Orthopedics n.a. N.N. Priorov, Moscow, Russian Federation,

Email: 10otdcito@mail.ru

6. Yulia V. Gavrilova, M.D.

National Medical Research Center of Traumatology and Orthopedics n.a. N.N. Priorov, Moscow, Russian Federation 